\title{
Prediction of Dansgaard-Oeschger Events From Greenland Dust Records
}

Lohmann, Johannes

Published in:

Geophysical Research Letters

DOI:

10.1029/2019GL085133

Publication date:

2019

Document version

Publisher's PDF, also known as Version of record

Citation for published version (APA):

Lohmann, J. (2019). Prediction of Dansgaard-Oeschger Events From Greenland Dust Records. Geophysical Research Letters, 46(12), 427-434. https://doi.org/10.1029/2019GL085133 


\title{
Geophysical Research Letters
}

\section{RESEARCH LETTER \\ 10.1029/2019GL085133}

\section{Prediction of Dansgaard-Oeschger Events From Greenland Dust Records}

\author{
Johannes Lohmann 1 (iD \\ ${ }^{1}$ Physics of Ice, Climate and Earth, Niels Bohr Institute, University of Copenhagen, Copenhagen, Denmark
}

Correspondence to: J. Lohmann,

johannes.lohmann@nbi.ku.dk

Citation:

Lohmann, J. (2019). Prediction of Dansgaard-Oeschger events from Greenland dust records. Geophysical Research Letters, 46, 12,427-12,434. https://doi.org/10.1029/2019GL085133

Received 22 AUG 2019 Accepted 23 OCT 2019 Accepted article online 9 NOV 2019 Published online 11 NOV 2019

(C)2019. American Geophysical Union. All Rights Reserved.

\begin{abstract}
The Dansgaard-Oeschger cycles of the last glacial period are attributed to changes in the Atlantic overturning circulation. An outstanding problem is whether these are driven by a self-sustained oscillation of the Earth system, by stochastic perturbations in terms of freshwater discharges into the ocean or extremes in atmospheric dynamics, or by another driver. Their complex temporal pattern suggests that the transitions in between cold (stadial) and warm (interstadial) phases are noise induced and thus unpredictable. Here, evidence is presented that this is unlikely because the transitions can be predicted to a certain degree within a few hundred years after stadial onset from consistent trends in Greenland dust proxies. These trends could be a manifestation of the climate system reorganizing at a specific timescale. What physically determines these highly variable timescales remains unexplained. Nevertheless, constraining the dynamics underlying these abrupt climate changes is an important step to uncover their causes.

Plain Language Summary The Dansgaard-Oeschger events of the last glacial period are the most significant abrupt, large-scale climate changes known. Although they occurred during different climatic background conditions, they are invaluable for benchmarking climate models used to predict anthropogenic climate change and for better understanding tipping points. Changes in ocean circulation are believed to bring about the large temperature contrasts. Climate models can reproduce such changes, but it is not agreed on whether these should be driven by self-sustained oscillations of the ocean, or excitations out of one climate regime to another by random perturbations of the atmosphere or ice sheets, among other things. Here, Greenland ice core data are used to constrain the scenarios. It is shown that the transitions can be predicted from gradual trends in dust records, which is in contrast to the latter hypothesis of random perturbations.
\end{abstract}

\section{Introduction}

The climate of the Last Glacial has been very unstable due to climate changes known as Dansgaard-Oeschger (DO) cycles. These abrupt transitions provide a unique example of large-scale climate change on centennial time scales and less. While their abruptness might be explained by sea ice retreat (Dokken et al., 2013; Li et al., 2010; Petersen et al., 2013), the large-scale pattern has been associated with changes in between two configurations of the Atlantic Meridional Overturning Circulation (AMOC; Broecker et al., 1985; Lynch-Stieglitz, 2017). However, it is debated what ultimately drives these changes, and recent climate model experiments offer different scenarios of what dynamics underlie DO cycles.

Many numerical models induce DO-like AMOC transitions via prescribed freshwater forcing (Ganopolski \& Rahmstorf, 2001; Kageyama et al., 2013). Similar transitions have been induced with forced variations of ice sheet topography (Zhang et al., 2014) and $\mathrm{CO}_{2}$ (Zhang et al., 2017). On the other hand, recent model experiments show unforced, near-periodic oscillations of the AMOC (Klockmann et al., 2018; Vettoretti \& Peltier, 2016). Furthermore, spontaneous transitions have been observed in climate models induced by the chaotic atmospheric forcing, acting as noise on the slower oceanic processes (Drijfhout et al., 2013; Kleppin et al., 2015).

Greenland ice core data provide important constraints to these scenarios. Model comparison studies indicate that climatic noise plays a prominent role to explain the irregular temporal evolution of the DO cycles (Mitsui \& Crucifix, 2017; Kwasniok, 2013; Lohmann \& Ditlevsen, 2019). Furthermore, a pacing of DO cycles by multiples of an external forcing period via stochastic resonance (Alley et al., 2001) was rejected in favor of 


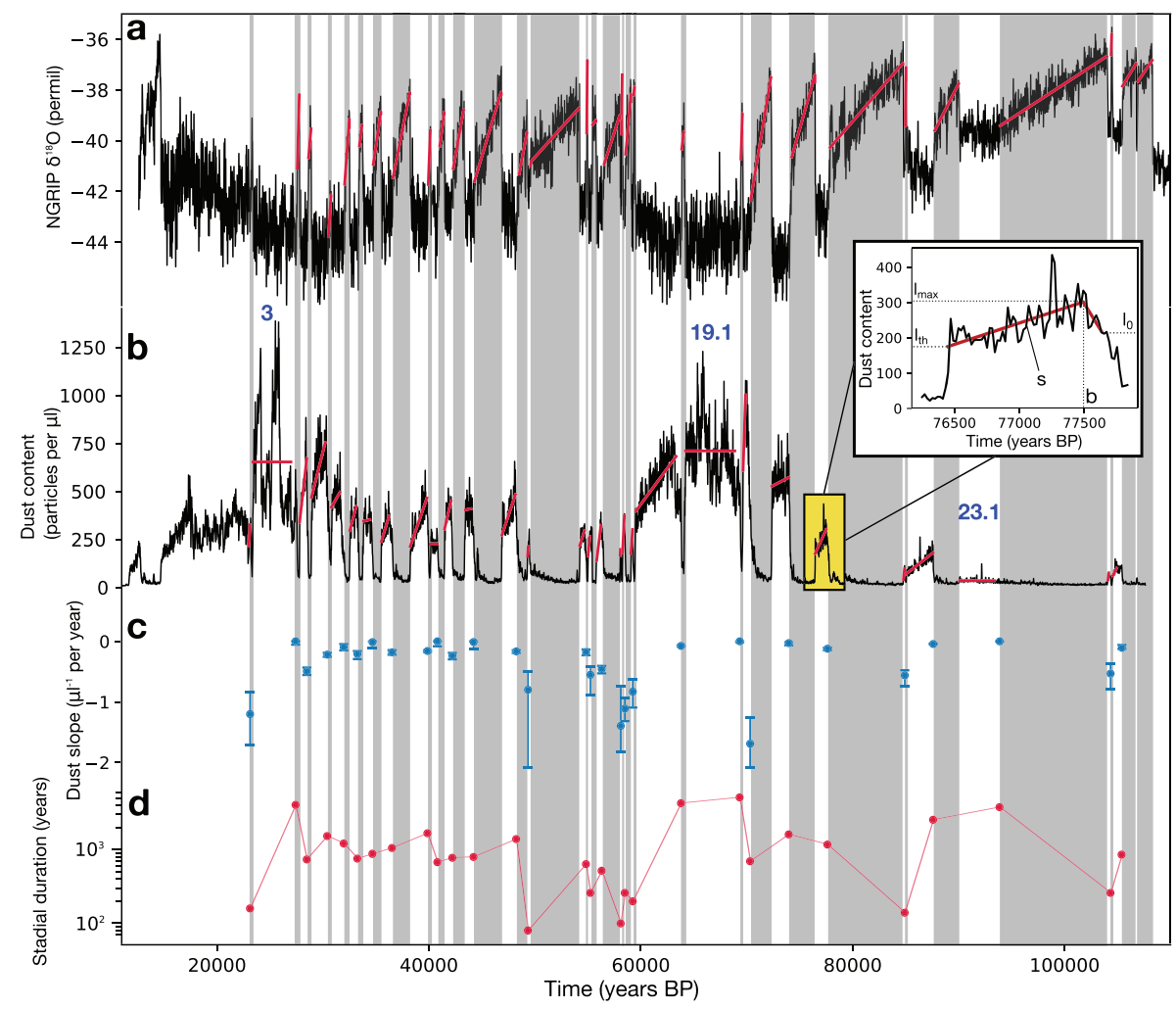

Figure 1. (a) NGRIP $\delta^{18} \mathrm{O}$ time series of the last glacial (NGRIP Members, 2004) with interstadial trends estimated in LD19. (b) NGRIP dust time series with stadial trends estimated in this paper. Gray bands indicate the interstadials identified in LD19 based on the classification by Rasmussen et al. (2014). The inset shows the piecewise linear fit and corresponding parameters for GS-21.1, that is used to estimate the stadial trends $s$. (c) Time series of the stadial slopes $s$ in the NGRIP dust record including uncertainties (16th to 84th percentile of the bootstrap samples). (d) Time series of the stadial durations from LD19.

a purely noise induced scenario (Ditlevsen et al., 2005; Ditlevsen et al., 2007), which had been suggested previously (Cessi, 1994; Ditlevsen, 1999; Timmermann \& Lohmann, 2000) and was shown to be consistent with statistical properties of the ensemble of DO cycles (Ditlevsen \& Johnsen, 2010; Lohmann \& Ditlevsen, 2019). Such noise-induced transitions should be entirely unpredictable. However, a recent study by Lohmann and Ditlevsen (2019, LD19 hereafter) showed that the DO cooling transitions are predictable by linear trends of the North Greenland Ice Core Project (NGRIP) $\delta^{18}$ O record in the preceding warm (interstadial) periods. The $\delta^{18} \mathrm{O}$ is a proxy for temperature at the deposition site and does not show consistent trends during the cold (stadial) periods preceding the DO warmings. Instead, this study addresses the predictability of these transitions by trends in dust and calcium proxies, which indicate changes in atmospheric circulation, influenced by changes in source area and transport (Schüpbach et al., 2018) and which show very pronounced responses to the DO cycles. Figures $1 \mathrm{a}$ and $1 \mathrm{~b}$ show the trends of $\delta^{18} \mathrm{O}$ in interstadials from LD19 together with the NGRIP dust trends during stadials, estimated in this study. These trends are consistently negative and roughly linear, with notable exceptions of stadials 3, 19.1, and 23.1, which show a more complicated structure. The main finding of this paper is that the linear dust/calcium trends successfully predict the onset of DO warmings. As a result, these cannot be purely noise induced.

\section{Methods and Materials}

\subsection{Data}

This work is based on dust and calcium records of Greenland ice cores. These are very similar on time scales relevant for the analysis, and calcium can be seen as a proxy for mineral dust (Ruth et al., 2002). In this paper both are colloquially referred to as dust if no specific data set is addressed. From NGRIP, dust (Ruth et al., 2003) and calcium (Rasmussen et al., 2014) records in 20-year binned resolution, in the time interval from 22.8 to $107.6 \mathrm{kyr}$ BP, are used. Calcium records of the Greenland Ice Core Project (GRIP) (Fuhrer et al., 1993) 
Table 1

Number of Events With Negative/Positive Stadial Slopes (Estimated From the Last Two Thirds of the Stadials), and Correlation of Stadial Dust Parameters

\begin{tabular}{|c|c|c|c|c|c|}
\hline \multirow[t]{2}{*}{ Ice core } & \multirow[t]{2}{*}{ Proxy } & \multirow{2}{*}{$\begin{array}{c}\text { Negative (pos.) } \\
\text { slope stadials }\end{array}$} & \multicolumn{3}{|c|}{ Spearman correlation } \\
\hline & & & Slope-duration & Threshold-duration & Threshold-maximum \\
\hline NGRIP & Dust & $26(4)$ & $0.797^{*}$ & $0.463^{* *}$ & $0.907^{*}$ \\
\hline NGRIP & Calcium & $26(4)$ & $0.725^{*}$ & $0.473^{* *}$ & $0.847^{*}$ \\
\hline GRIP & Calcium & $21(7)$ & $0.576^{*}$ & $0.427^{* *}$ & $0.721^{*}$ \\
\hline GISP2 & Calcium & $24(4)$ & $0.821^{*}$ & $0.414^{* *}$ & $0.765^{*}$ \\
\hline NEEM & Calcium & $25(5)$ & $0.635^{*}$ & $0.443^{* *}$ & $0.808^{*}$ \\
\hline
\end{tabular}

*Indicates $p<0.01$, obtained from a permutation test. ${ }^{* *}$ Indicates $p<0.05$, obtained from a permutation test.

and Greenland Ice Sheet Project (GISP2) (Mayewski et al., 1997) ice cores in 20-year binned resolution are used from 22.8 to 104.0 kyr BP. Furthermore, the calcium record of the North Greenland Eemian Ice Drilling (NEEM) ice core in 10-year binned resolution from 22.8 to $104.0 \mathrm{kyr}$ BP is used (Schüpbach et al., 2018).

All proxies are on the GICC05modelext time scale (Rasmussen et al., 2013, 2014; Svensson et al., 2006; Seierstad et al., 2014) and sampled at the midpoint of the time bin intervals. Missing data are interpolated linearly. The classification of the last glacial into Greenland stadials (GS) and interstadials (GI), including the two quasi-stadials GS-14 and GS-23.1, is adopted from Rasmussen et al. (2014). The timings of stadial onset and end used in this study have been derived from a continuous piecewise linear fit to the highest-resolution NGRIP $\delta^{18} \mathrm{O}$ record in LD19. This fit divides each DO cycle into four linear segments: a gradual interstadial cooling; an abrupt cooling phase at the end of which the stadial onset is defined; a constant stadial phase; and an abrupt warming phase at the start of which the stadial end is defined. All stadials from GS-2.2 until GS-24.1 are considered in this work. GS-2.1 is excluded from the analysis due to difficulties in extracting the timings of the adjacent interstadials from the piecewise linear fit in LD19.

\subsection{Piecewise Linear Fit}

Two linear segments are fit to the stadial proxy data, consisting of an upward trend starting at a dust level $l_{0}$ at the stadial beginning, a break point at time $b$ and maximum dust level $l_{\max }$, and a downward trend until the stadial end at the dust threshold value $l_{\text {th }}$. A corresponding fit with these four parameters can be seen in the inset of Figure $1 \mathrm{~b}$ for GS-21.1. The slopes are defined as $s=\left(l_{\text {th }}-l_{\max }\right) \cdot(D-b)^{-1}$, where $D$ is the stadial duration from LD19. The break point is constrained to be no later than 500 years and no earlier than 20 years after stadial onset, as well as no later than 40 years before stadial end, in order to obtain well-defined upward and downward segments in cases of stadials with more complicated structure, such as GS-3, 19.1, and 23.1. The fit is defined on a 1-year grid, allowing for breakpoints in between two data points. The root-mean-square deviation (RMSD) of fit and data is minimized subject to the above mentioned constraints by the global optimization routine basin hopping (Olson et al., 2012).

Parameter uncertainties are estimated via bootstrap block resampling. For each stadial fit, the residuals are divided in blocks of length corresponding to the time scale of nonsignificant autocorrelation. For most stadials this yields 20 years (one data point), and 40-80 years for a few others. For stadials GS-3, GS-18, and GS-19.1 a block length of 200 years is used. After resampling the blocks, the piecewise linear fit is added and the fitting procedure is performed to obtain new parameter samples.

\section{Results}

\subsection{Correlation of Dust Trends and Stadial Durations}

The rapid cooling phases of the $\delta^{18} \mathrm{O}$ record preceding stadial onsets are accompanied by rapid increases in dust from low interstadial values. After stadial onset, as defined from $\delta^{18} \mathrm{O}$, dust continues to rise for typically 50 to 300 years. Thereafter, most stadials show a negative dust slope. When linearly fitting the last two thirds of each stadial, the clear majority of stadials yield a negative slope for all proxies, as listed in Table 1. To better quantify the slopes a break is fit to each stadial, as detailed in section 2.2. The fits to all stadials and proxies are shown in the supporting information. The resulting slopes show a significant 

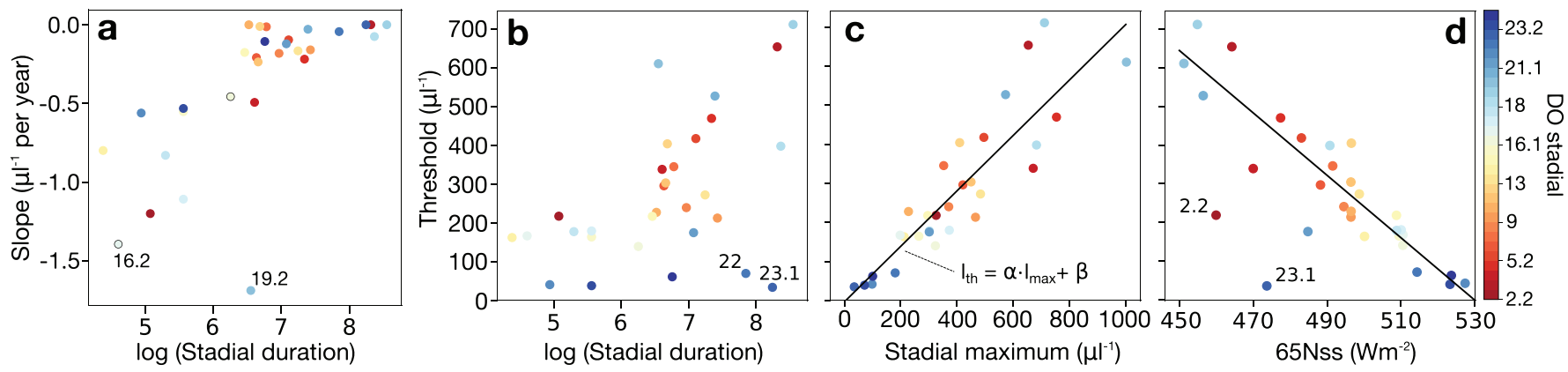

Figure 2. (a, b) Scatterplots of the piecewise linear fit parameters of the NGRIP dust record. (c) Linear relationship of the thresholds $l_{\text {th }}$ and maxima $l_{\text {max }}$, and a linear fit $l_{\text {th }}=\alpha \cdot l_{\max }+\beta$ with $\alpha=0.71$ and $\beta=-3.42$. (d) Linear relationship of the thresholds $l_{\text {th }}$ and 65 Nss at the time of stadial maximum.

(at least 99\% confidence) nonlinear correlation with the stadial durations, as shown in Table 1. For the NGRIP dust record, time series of the slopes and the durations are shown in Figures 1c and 1d. A corresponding scatterplot is shown in Figure 2a, and all fit parameters are listed in Table S1 in the supporting information.

The stadial durations also correlate with the thresholds at the DO onsets $l_{\mathrm{th}}$, as shown in Figure $2 \mathrm{~b}$, and equally with the stadial maxima $l_{\max }$. This correlation is weaker than that of durations and slopes. Thus, mainly the time scale set by the slope determines the stadial duration, while additional information is embedded in the threshold and maximum, which themselves are strongly related, as seen in Table 1 and Figure 2c.

\subsection{Influence of External Forcing}

The variability in the slopes cannot be explained by common external forcings, as shown by correlating the slopes with different forcings at the times of the dust maxima. These include proxies for global ice volume (LR04, Raymo \& Lisiecki, 2005), Antarctic temperature (EDML, EPICA Community Members, 2010), $\mathrm{CO}_{2}$ (Bereiter et al., 2015), integrated insolation at $65^{\circ} \mathrm{N}$ on days exceeding $350 \mathrm{~W} / \mathrm{m}^{2}$ (65Nint, Huybers, 2006), and daily mean insolation at $65^{\circ}$ North on summer solstice (65Nss, Laskar et al., 2004), as well as raw orbital parameters (Laskar et al., 2004). The largest Spearman correlation averaged over all dust proxies is found for precession $\left(r_{S}=0.286\right)$. However, for the individual proxies this is not significant at $95 \%$ confidence. The only forcings that significantly correlate with the slopes are $65 \mathrm{Nint}$ and $65 \mathrm{Nss}$ for the GISP2 Ca record with $r_{S}=-0.402$ and $r_{S}=-0.437$, respectively, which are likely false positives.

On the other hand, the evolution of both maxima and thresholds is explained well by insolation forcing. For the thresholds, the average correlations for $65 \mathrm{Nint}, 65 \mathrm{Nss}$, and obliquity are $r_{S}=0.643, r_{S}=0.610$, and $r_{S}=0.553$, respectively. Figure $2 \mathrm{~d}$ illustrates the linear relationship of the thresholds and $65 \mathrm{Nss}$. Discarding two outliers, the Pearson correlation is $r_{P}=0.918$. The maxima and thresholds of most proxies also correlate significantly with LR04, EDML, and $\mathrm{CO}_{2}$. However, the correlation coefficients are lower and are dominated by a common linear trend and an obliquity component of the forcings. Thus, via the thresholds, the stadial durations are modulated by insolation, in agreement with Lohmann and Ditlevsen (2018) and LD19. Still, due to the irregular evolution of the slopes, the stadial durations show a large variability that is not explained by insolation forcing.

Finally, it is tested whether the presence of Heinrich events (Heinrich, 1988) significantly influences the stadial dust signal. Following Seierstad et al. (2014), the Heinrich events H2, H3, H4, H5a, H5, H6, H7a, $\mathrm{H} 7 \mathrm{~b}$, and $\mathrm{H} 8$ occur during the stadials 3, 5.2, 9, 13, 15.1, 18, 20, 21.1, and 22, respectively. Using a bootstrap resampling test with respect to the mean or median of these stadials, all proxies indicate that neither the dust slopes, maxima, nor thresholds of stadials with Heinrich events are significantly different from the rest. If, however, only the more established Heinrich events $\mathrm{H} 2, \mathrm{H} 3, \mathrm{H} 4, \mathrm{H} 5$, and $\mathrm{H} 6$ are used, the maxima and thresholds are significantly larger at $95 \%$ and $90 \%$ confidence, respectively.

\subsection{Predictability of DO Warmings}

Even though this paper cannot explain the irregular evolution of the trends from one stadial to the next, they represent a time scale in the climate system determining the time of DO onset. The trends are linear enough so that this time scale can be extracted already quite early within the stadials, and thus the DO onsets are to 


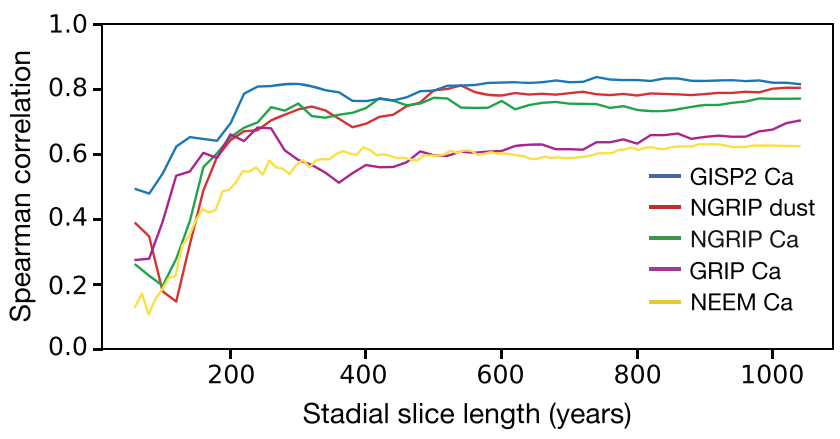

Figure 3. Spearman correlation of dust slopes estimated from stadial slices as a function of slice length for the different records. For stadials shorter than the slice length, the full stadial is used.

some degree predictable. To show this, a linear fit is performed on short slices of each stadial after the break point $b$, and the estimated slopes are correlated with the durations of the respective stadials. Figure 3 shows that for increasing slice length this correlation saturates and reaches its final value after $250-400$ years for all proxies.

In conjunction with the fact that the stadial maxima correlate linearly with the thresholds, the previous result can be used to predict the stadial durations. The duration of a given stadial is $D=\left(l_{\text {th }}-l_{\max }\right) \cdot s^{-1}+b$. All variables on the right-hand side can be estimated from a data slice covering the beginning of the stadial plus information about $l_{\max }$ and $l_{\text {th }}$ of the preceding stadials. The slice is chosen according to Figure 3 , which for the NGRIP dust records yields 320 years plus the period of dust increase before the break point. For the nine stadials that have a length after the break point of less than 320 years, a slice is chosen that ends 20 years before the last data point. From these slices, we reestimate the breakpoints $\hat{b}$ with a piecewise linear fit, and then estimate the maxima $\hat{l}_{\max }$ and slopes $\hat{s}$ with a linear fit to the segment after $\hat{b}$. The stadials 3, 11, 19.1, and 23.1 are excluded, because they do not yield a downward slope and thus a negative predicted duration. Finally, the threshold is predicted by $\hat{l}$ th $=\hat{\alpha} \cdot \hat{l}_{\max }+\hat{\beta}$. The $\hat{\alpha}$ and $\hat{\beta}$ are obtained by a linear regression of $\hat{l}_{\max }$ and $l_{\mathrm{th}}$ analogously to Figure 2c, except that only stadials occurring earlier in time are used. This prediction forward in time starts with GS-22, but an exception is made for the earliest stadials 24.1 and 23.2, where the regression is based on all stadials except the one to be predicted. The prediction is thus $\hat{D}=\left(\hat{l}_{\mathrm{th}}-\hat{l}_{\max }\right) \cdot \hat{s}^{-1}+\hat{b}$. The resulting event series is shown in Figures $4 \mathrm{a}$ and $4 \mathrm{~b}$. The different orders of magnitude and the overall evolution of the durations are well captured, as seen with the logarithmic scale in Figure $4 \mathrm{~b}$. The largest
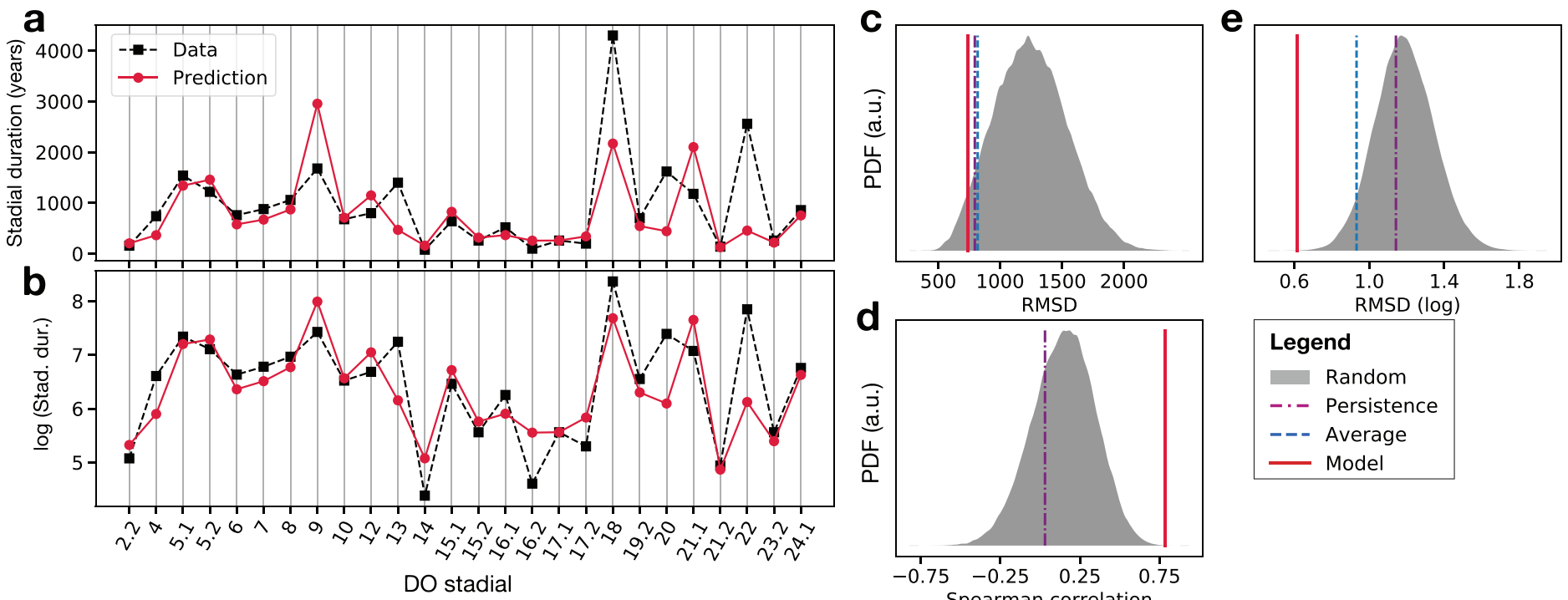

Figure 4. Stadial durations predicted by the model (see main text) and data (LD19) in (a) true and (b) logarithmic scale. (c-e) Skill comparison of the prediction model (red) against three null models (see main text) using three different scores. The random model yields distributions of scores (gray), whereas the other two null models result in point estimates. 
discrepancies arise due to underestimation (GS-9) or overestimation (GS-13, GS-18, GS-20, and GS-22) of the true slopes with the short stadial slices.

The predictive skill is assessed by three scores: the RMSD, the RMSD of the logarithm, and the Spearman correlation of predicted and true durations. These values are compared with three null models. First, a random model where 30 samples are drawn repeatedly with replacement from the distribution of stadial durations, yielding a distribution of scores. Second, a persistence model, which always predicts the value of the preceding stadial. Third, an average model, where for any stadial the mean of the remaining stadials is predicted. We exclude the four worst predictions in terms of the squared deviation from the calculation of the scores in order to correct for the fact that we had to discard four stadials in our model predictions. The results in Figures $4 \mathrm{c}-4 \mathrm{e}$ show that the model performs significantly better $(p=0.037$ for RMSD, and $p<0.001$ for the other scores) than the random model and also clearly better than the persistence and average models.

\section{Discussion}

Gradual interstadial cooling trends in Greenland $\delta^{18} \mathrm{O}$ records have previously been associated with interstadial durations and the background climate (Schulz, 2002; Buizert \& Schmittner, 2015). Due to the linearity of these trends, it follows that the timing of the DO cooling transitions are predetermined rather early after interstadial onset (LD19). The present paper shows that the same holds for DO warming transitions, which can be predicted already several hundred years after stadial onset with significant skill due to consistent decreases of dust in almost all stadials. Even though the predictions of the deterministic model are not perfect, and thus there remains room for a stochastic influence potentially delaying or advancing individual DO onsets, a scenario of entirely spontaneous (unpredictable) DO warming or cooling transitions induced by noise is unlikely. Further support comes from increases in high-frequency $\delta^{18} \mathrm{O}$ variance leading up to some DO warmings, which might be due to destabilization of a fast subsystem of the climate, such as sea ice (Boers, 2018; Rypdal, 2016). Thus, there must be a different mechanism giving rise to the variability of stadial and interstadial timescales, which cannot be explained by common external forcings alone (LD19 and section 3.2).

The results contrast Mogensen et al. (2002), who report average stadial calcium trends in GRIP close to zero. This is mostly because short dust increases after stadial onsets are considered here, which are present in almost all stadials, and because the GRIP calcium record shows the weakest trends among all proxies. Dust trends have been furthermore extracted using a different method and linked to Antarctic climate by a lagged correlation analysis (Barker \& Knorr, 2007). A preliminary analysis using the WAIS $\delta^{18} \mathrm{O}$ record indicates that beyond this correlation, the Antarctic stadial trends do not hold the same information as the Greenland dust trends, and cannot predict the stadial durations. The same is true for stadial trends in the $\mathrm{CO}_{2}$ record.

In the analysis, certain outliers had to be discarded. Stadials 3 and 19.1 show more complicated structure and thus cannot be predicted relying on linear slopes. Furthermore, the fact that GS-23.1 does not follow the dust trends generic to other stadials is likely a result of the uncertainty in defining GS-23.1 from the $\delta^{18} \mathrm{O}$ record in LD19. The presence of outliers can, on the other hand, indicate that some DO cycles have different drivers.

Whereas Erhardt et al. (2019) report that Greenland temperature shifts are preceded by changes in atmospheric conditions, due to average 10 year leads of calcium and accumulation rate shifts, the current results show that dust in fact already decreases throughout the stadial. Even though the understanding of the dust proxy needs to be improved, the consistency of the stadial trends suggests that they robustly record gradual, large-scale changes. The recent study by Schüpbach et al. (2018) concludes that interstadial-stadial changes in Greenland dust are mostly due to stronger winds in the Asian desert regions combined with higher aridity and a strengthening or shift of the jet stream. Thus, the stadial trends could capture decreases or positional shifts in midlatitude wind, which might be due to growing ice sheets as found in the modeling study by Zhang et al. (2014). There, a reduction in wind-driven sea ice import to the North Atlantic led to DO-like transitions. Gradual sea ice decrease during stadials is seen in North Atlantic proxies (Sadatzki et al., 2019). AMOC strengthening as a response to changing wind stress due to ice sheet growth seems to be a common feature among models (Muglia \& Schmittner, 2015; Sherriff-Tadano et al., 2018). The ice sheet changes could in turn be a response to temperature changes after AMOC regime shifts. However, the evolution of ice sheets during DO cycles still needs to be constrained better. 


\section{Conclusion}

This study presents evidence for predictability of DO warming transitions due to consistent trends in Greenland ice core dust records, which can be observed already within a few hundred years after stadial onset. The same has been observed in LD19 for DO cooling transitions due to oxygen isotope trends. Thus, the DO transitions cannot be purely noise induced. With few exceptions, each DO event forms a consistent cycle with two independent time scales seen in oxygen isotope and dust trends, respectively, and rapid transitions in between. The complex temporal pattern, that is, what physically determines the time scale of the individual DO excursions remains to be explained.

Acknowledgments

This work has been supported by the Villum Foundation under Grant 17470. All ice core data used in this study are publicly available at http:// iceandclimate.nbi.ku.dk/data/, except for the NEEM data, which is available as supporting information at this site (https://doi.org/10.1038/ s41467-018-03924-3).

\section{References}

Alley, R. B., Anandakrishnan, S., \& Jung, P. (2001). Stochastic resonance in the North Atlantic. Paleoceanography, 16(2), 190-198. Barker, S., \& Knorr, G. (2007). Antarctic climate signature in the Greenland ice core record. PNAS, 104(44), 17,278-17,282.

Bereiter, B., Eggleston, S., Schmitt, J., Nehrbass-Ahles, C., Stocker, T. F., Fischer, H., et al. (2015). Revision of the EPICA Dome C CO 2 record from 800 to $600 \mathrm{kyr}$ before present. Geophysical Research Letters, 42, 542-549. https://doi.org/10.1002/2014GL061957

Boers, N. (2018). Early-warning signals for Dansgaard-Oeschger events in a high-resolution ice core record. Nature Communications, 9 , 2556.

Broecker, W. S., Peteet, D. M., \& Rind, D. (1985). Does the ocean-atmosphere system have more than one stable mode of operation? Nature, 315, 21-26.

Buizert, C., \& Schmittner, A. (2015). Southern Ocean control of glacial AMOC stability and Dansgaard-Oeschger interstadial duration. Paleoceanography, 30, 1595-1612. https://doi.org/10.1002/2015PA002795

Cessi, P. (1994). A simple box model of stochastically forced thermohaline flow. Journal of Physical Oceanography, $24,1911$.

Ditlevsen, P. D. (1999). Observation of $\alpha$-stable noise induced millenial climate changes from an ice-core record. Geophysical Research Letters, 26(10), 1441-1444.

Ditlevsen, P. D., Andersen, K. K., \& Svensson, A. (2007). The DO-climate events are probably noise induced: Statistical investigation of the claimed 1470 years cycle. Climate of the Past, 3, 129-134.

Ditlevsen, P. D., \& Johnsen, S. J. (2010). Tipping points: Early warning and wishful thinking. Geophysical Research Letters, 37, L19703. https://doi.org/10.1029/2010GL044486

Ditlevsen, P. D., Kristensen, M. S., \& Andersen, K. K. (2005). The recurrence time of Dansgaard-Oeschger events and limits on the possible periodic component. Journal of Climate, 18, 2594-2603.

Dokken, T. M., Nisancioglu, K. H., Li, C., Battisti, D. S., \& Kissel, C. (2013). Dansgaard-Oeschger cycles: Interactions between ocean and sea ice intrinsic to the Nordic seas. Paleoceanography, 28, 491-502. https://doi.org/10.1002/palo.20042

Drijfhout, S., Gleeson, E., Dijkstra, H. A., \& Livina, V. (2013). Spontaneous abrupt climate change due to an atmospheric blocking-sea-ice-ocean feedback in an unforced climate model simulation. PNAS, 110(49), 19,713-19,718

EPICA Community Members (2010). Stable oxygen isotopes of ice core EDML. PANGAEA. https://doi.org/10.1594/PANGAEA.754444

Erhardt, T., Capron, E., Rasmussen, S. O., Schüpbach, S., Bigler, M., Adolphi, F., \& Fischer, H. (2019). Decadal-scale progression of the onset of Dansgaard-Oeschger warming events. Climate of the Past, 15, 811-825.

Fuhrer, K., Neftel, A., Anklin, M., \& Maggi, V. (1993). Continuous measurements of hydrogen peroxide, formaldehyde, calcium and ammonium concentrations along the new GRIP ice core from Summit, Central Greenland. Atmospheric Environment, A27, 1873-1880.

Ganopolski, A., \& Rahmstorf, S. (2001). Rapid changes of glacial climate simulated in a coupled climate model. Nature, 409, 153-158.

Heinrich, H. (1988). Origin and consequences of cyclic ice rafting in the northeast Atlantic Ocean during the past 130,000 years. Quaternary Research, 29(2), 142-152.

Huybers, P. (2006). Early Pleistocene glacial cycles and the integrated summer insolation forcing. Science, 313, 508-511.

Kageyama, M., Merkel, U., Otto-Bliesner, B., Prange, M., Abe-Ouchi, A., Lohmann, G., et al. (2013). Climatic impacts of fresh water hosing under Last Glacial Maximum conditions: A multi-model study. Climate of the Past, 9, 935-953.

Kleppin, H., Jochum, M., Otto-Bliesner, B., Shields, C. A., \& Yeager, S. (2015). Stochastic atmospheric forcing as a cause of Greenland climate transitions. Journal of Climate, 28, 7741-7763.

Klockmann, M., Mikolajewicz, U., \& Marotzke, J. (2018). Two AMOC states in response to decreasing greenhouse gas concentrations in the coupled climate model MPI-ESM. Journal of Climate, 31, 7969-7984.

Kwasniok, F. (2013). Analysis and modelling of glacial climate transitions using simple dynamical systems. Philosophical Transactions of the Royal Society A: Mathematical, Physical and Engineering Sciences, 371, 20110472.

Laskar, J., Robutel, P., Joutel, F., Gastineau, M., Correia, A. C. M., \& Levrard, B. (2004). A long term numerical solution for the insolation quantities of the Earth. Astronomy and Astrophysics, 428, 261-285.

Li, C., Battisti, D. S., \& Bitz, C. M. (2010). Can North Atlantic sea ice anomalies account for Dansgaard-Oeschger climate signals? Journal of Climate, 23, 5457-5475.

Lohmann, J., \& Ditlevsen, P. D. (2018). Random and externally controlled occurrences of Dansgaard-Oeschger events. Climate of the Past, 14(5), 609-617.

Lohmann, J., \& Ditlevsen, P. D. (2019). A consistent statistical model selection for abrupt glacial climate changes. Climate Dynamics, 52, 6411-6426.

Lohmann, J., \& Ditlevsen, P. D. (2019). Objective extraction and analysis of statistical features of Dansgaard-Oeschger events. Climate of the Past, 15(5), 1771-1792.

Lynch-Stieglitz, J. (2017). The Atlantic meridional overturning circulation and abrupt climate change. Annual Review of Marine Science, 9 , 83-104.

Mayewski, P. A., Meeker, L. D., Twickler, M. S., Whitlow, S., Yang, Q., Lyons, W. B., \& Prentice, M. (1997). Major features and forcing of high-latitude Northern Hemisphere atmospheric circulation using a 110,000-year-long glaciochemical series. Journal of Geophysical Research, 102(C12), 26,345-26,366.

Mitsui, T., \& Crucifix, M. (2017). Influence of external forcings on abrupt millennialâĂ ̌̌scale climate changes: A statistical modelling study. Climate Dynamics, 48, 2729. 
Mogensen, I. A., Johnsen, S. J., Ganopolski, A., \& Rahmstorf, S. (2002). An investigation of rapid warm transitions during MIS2 and MIS3 using Greenland ice-core data and the CLIMBER-2 model. Annals of Glaciology, 35, 398-402.

Muglia, J., \& Schmittner, A. (2015). Glacial Atlantic overturning increased by wind stress in climate models. Geophysical Research Letters, 42, 9862-9869. https://doi.org/10.1002/2015GL064583

NGRIP Members (2004). High-resolution record of Northern Hemisphere climate extending into the last interglacial period. Nature, 431, $147-151$.

Olson, B., Hashmi, I., Molloy, K., \& Shehu, A. (2012). Basin hopping as a general and versatile optimization framework for the characterization of biological macromolecules. Advances in Artificial Intelligence, 2012, 674832.

Petersen, S. V., Schrag, D. P., \& Clark, P. U. (2013). A new mechanism for Dansgaard-Oeschger cycles. Paleoceanography, 28, 24-30. https:// doi.org/10.1029/2012PA002364

Rasmussen, S. O., et al. (2013). A first chronology for the North Greenland Eemian Ice Drilling (NEEM) ice core. Climate of the Past, 9 , 2713-2730.

Rasmussen, S. O., Bigler, M., Blockley, S. P., Blunier, T., Buchardt, S. L., Clausen, H. B., et al. (2014). A stratigraphic framework for abrupt climatic changes during the Last Glacial period based on three synchronized Greenland ice-core records: Refining and extending the INTIMATE event stratigraphy. Quaternary Science Reviews, 106, 14-28.

Raymo, M. E., \& Lisiecki, L. E. (2005). A Pliocene-Pleistocene stack of 57 globally distributed benthic $\delta^{18}$ O records. Paleoceanography, 20, PA1003. https://doi.org/10.1029/2004PA001071

Ruth, U., Wagenbach, D., Bigler, M., Steffensen, J. P., Röthlisberger, R., \& Miller, H. (2002). High-resolution microparticle profiles at NorthGRIP, Greenland: Case studies of the calcium-dust relationship. Annals of Glaciology, 35, 237-242.

Ruth, U., Wagenbach, D., Steffensen, J. P., \& Bigler, M. (2003). Continuous record of microparticle concentration and size distribution in the central Greenland NGRIP ice core during the last glacial period. Journal of Geophysical Research, 108(D3), 4098. https://doi.org/10. 1029/2002JD002376

Rypdal, M. (2016). Early-warning signals for the onsets of greenland interstadials and the Younger Dryas-Preboreal transition. Journal of Climate, 29, 4047-4056.

Sadatzki, H., Dokken, T. M., Berben, S. M. P., Muschitiello, F., Stein, R., Fahl, K., et al. (2019). Sea ice variability in the southern Norwegian Sea during glacial Dansgaard-Oeschger climate cycles. Science Advances, 5, eaau6174.

Schulz, M. (2002). The tempo of climate change during Dansgaard-Oeschger interstadials and its potential to affect the manifestation of the 1470-year climate cycle. Geophysical Research Letters, 29(1), 1002. https://doi.org/10.1029/2001GL013277

Schüpbach, S., Fischer, H., Bigler, M., Erhardt, T., Gfeller, G., Leuenberger, D., et al. (2018). Greenland records of aerosol source and atmospheric lifetime changes from the Eemian to the Holocene. Nature Communications, 9, 1476.

Seierstad, I. K., Abbott, P. M., Bigler, M., Blunier, T., Bourne, A. J., Brook, E., et al. (2014). Consistently dated records from the Greenland GRIP, GISP2 and NGRIP ice cores for the past $104 \mathrm{ka}$ reveal regional millennial-scale $\delta^{18} \mathrm{O}$ gradients with possible Heinrich event imprint. Quaternary Science Reviews, 106, 29-46.

Sherriff-Tadano, S., Abe-Ouchi, A., Yoshimori, M., Oka, A., \& Chan, W.-L. (2018). Influence of glacial ice sheets on the Atlantic meridional overturning circulation through surface wind change. Climate Dynamics, 50, 2881-2903.

Svensson, A., Andersen, K. K., Bigler, M., Clausen, H. B., Dahl-Jensen, D., Davies, S. M., et al. (2006). The Greenland ice core chronology 2005, 15-42 ka. Part 2: Comparison to other records. Quaternary Science Reviews, 25, 3258-3267.

Timmermann, A., \& Lohmann, G. (2000). Noise-induced transitions in a simplified model of the thermohaline circulation. Journal of Physical Oceanography, 30, 1891-1900.

Vettoretti, G., \& Peltier, W. R. (2016). Thermohaline instability and the formation of glacial North Atlantic super polynyas at the onset of Dansgaard-Oeschger warming events. Geophysical Research Letters, 43, 5336-5344. https://doi.org/10.1002/2016GL068891

Zhang, X., Knorr, G., Lohmann, G., \& Barker, S. (2017). Abrupt North Atlantic circulation changes in response to gradual $\mathrm{CO}_{2}$ forcing in a glacial climate state. Nature Geoscience, 10, 518-523.

Zhang, X., Lohmann, G., Knorr, G., \& Purcell, C. (2014). Abrupt glacial climate shifts controlled by ice sheet changes. Nature, 512, $290-294$. 